\title{
ECKART, Wolfgang U., GRADMANN, Christoph, Ärztelexikon. Von der Antike bis zum 20. Jahrhundert
}

Isabelle von Bueltzingsloewen

\section{OpenEdition}

\section{Journals}

Édition électronique

URL : http://journals.openedition.org/ifha/1570

DOI : 10.4000/ifha.1570

ISSN : 2198-8943

Éditeur

IFRA - Institut franco-allemand (sciences historiques et sociales)

Référence électronique

Isabelle von Bueltzingsloewen, « ECKART, Wolfgang U., GRADMANN, Christoph, Ärztelexikon. Von der Antike bis zum 20. Jahrhundert ", Revue de l'IFHA [En ligne], Date de recension, mis en ligne le 01 janvier 1996, consulté le 22 septembre 2020. URL : http://journals.openedition.org/ifha/1570 ; DOI : https:// doi.org/10.4000/ifha. 1570

Ce document a été généré automatiquement le 22 septembre 2020.

(C)IFHA 
ECKART, Wolfgang U., GRADMANN, Christoph, Ärztelexikon. Von der Antike bis zum 20. Jahrhundert

Isabelle von Bueltzingsloewen 
Après la publication, dans une collection de poche facilement accessible, d'un dictionnaire des théologiens, d'un dictionnaire des historiens et plus récemment d'un dictionnaire de la résistance, la maison d'édition Beck poursuit sur sa lancée en éditant un dictionnaire des médecins de l'Antiquité à nos jours. Celui-ci regroupe près de 700 notices biographiques suivies d'indications bibliographiques, complétées par un index ainsi que par une liste des personnages recensés, classés par ordre chronologique. Sans doute la brièveté des notices ne dispensera-t-elle pas le chercheur de consulter des dictionnaires plus anciens mais plus complets, tels que celui d'August HIRSCH (Lexikon der hervorragenden Ärzte aller Zeiten und Völker, 5 t., Berlin, 1929-1935), sans doute certains spécialistes s'étonneront-ils de ne pas trouver répertorié tel ou tel médecin qu'ils considèrent comme majeur et contesteront-ils les critères de sélection des individus retenus qui privilégient les Allemands mais surtout laissent de côté les humbles et les modestes qui n'ont pas enrichi la connaissance médicale par quelque découverte. Cet ouvrage n'en est pas moins un instrument de repérage très commode pour tous ceux qui travaillent dans le champ de l'histoire médicale, apportant même des informations précieuses sur des catégories de médecins mal connues en particulier les femmes médecins et les médecins victimes de la persécution nazie. A côté des notices consacrées à Hippocrate, à Boerhaave, à Pinel, à Virchow ou à Koch, on lira ainsi avec un intérêt particulier la notice d'Agnès Bluhm, troisième femme à obtenir le diplôme de médecin en Allemagne, qui acquiert la notoriété grâce à ses travaux sur l'hygiène raciale et à son engagement en faveur de l'euthanasie appliquée aux malades incurables; ou encore celle de Rachel Hirsch, fille de rabbin, nommée en 1913 première femme professeur de médecine de Prusse (puis du IIIe Reich), forcée d'émigrer en Angleterre en 1938, qui meurt en 1953 dans une clinique psychiatrique près de Londres.

Isabelle von BUELZINGSLOEWEN 